\title{
REVALIDACIÓN DE TÍTULOS EXTRANJEROS EN CHILE
}

Jorge Litvak* Juan Carlos González 


\section{RESUMEN}

Este artículo presenta los antecedentes históricos del sistema de validación de títulos profesionales extranjeros en Chile. La Universidad de Chile, prácticamente desde su creación en 1842, ha ejercido la atribución de validar y reconocer los títulos profesionales y grados académicos obtenidos en el extranjero, con gran rigurosidad y exigencia académica. Se revisan los aspectos principales de reglamentos y procedimientos que rigen los reconocimientos y revalidaciones y se hace una síntesis de los principales tratados internacionales que el país ha suscrito, autorizando, recíprocamente, el ejercicio de profesionales extranjeros en su territorio.

\section{ABSTRACT}

This report presents the historical background of the foreign degrees' renewal in Chile. Since it was created, in 1842, the University of Chile has the function to recognize the professional and academic degrees obtained abroad, applying a serious and demanding pattern. The paper points out the most important rules and proceedings applied to recognitions and renewals, and offers a synthesis of the international agreements suscribed by our country authorising foreign professionals to work in either one. 


\section{REVALIDACIÓN DE TÍTULOS EXTRANJEROS EN CHILE}

\section{ANTECEDENTES}

El sistema de revalidación, reconocimiento y convalidación, en Chile, de títulos profesionales y grados académicos obtenidos en países del exterior que, en adelante, referiremos genéricamente como revalidación de títulos extranjeros, encuentra su actual fundamento legal en el artículo tercero del Decreto con Fuerza de Ley N 153 del año 1981, aprobatorio del Estatuto de la Universidad de Chile, que señala:

"A la Universidad de Chile le corresponde la atribución privativa y excluyente de reconocer, revalidar y convalidar títulos profesionales obtenidos en el extranjero, sin perjuicio de lo dispuesto en los tratados internacionales.

También le compete pronunciarse sobre convenios o tratados internacionales relativos a la educación superior que el gobierno de Chile tenga interés en suscribir con otros gobiernos o entidades internacionales y extranjeras".

Tal disposición tiene su antecedente histórico en un Decreto del Ministerio de Instrucción Pública, de 11 de septiembre de $1866^{1}$, que aprobó el reglamento sobre reconocimiento de universidades extranjeras elaborado por el Consejo de Instrucción Pública. En tal normativa se señalaba que el presidente de la República podía reconocer una o más facultades de una universidad extranjera, de acuerdo con

1 Marshall, Enrique L., Universidad de Chile, Leyes, Decretos y Reglamentos, Tomo I, Reglamentación General de los Servicios dependientes de Rectoría, Ed. Universitaria, Santiago de Chile, 1953. 
un procedimiento que buscaba establecer que la enseñanza impartida en ellas era equivalente a los estudios y planes respectivos de la Universidad de Chile ${ }^{2}$.

Entre 1862 y los primeros años del Siglo XX muchas instituciones fueron objeto de este reconocimiento, incluyendo a las principales universidades italianas (1868) y alemanas (1901), las de Havard, Yale y Columbia (1905), y la de París $(1909)^{3}$.

Esta potestad de la Universidad de Chile continuó en normativas posteriores sobre la materia. El Estatuto Orgánico de la Enseñanza Universitaria, dictado mediante Decreto con Fuerza de Ley $\mathrm{N}^{\circ} 280$, de 20 de mayo de 1931, estableció en su artículo 13 letra j), la facultad del Consejo Universitario de: "Reglamentar el reconocimiento y validación de exámenes, grados y títulos otorgados por universidades extranjeras, correspondientes a los que se otorgan en la Universidad de Chile y pronunciarse sobre las solicitudes que se presenten al respecto" ${ }^{4}$.

El estatuto del año 1931 fue remplazado en 1971 por el "Estatuto Orgánico de la Universidad de Chile", aprobado por Decreto con Fuerza de Ley $\mathrm{N}^{\circ} 1$ de ese año. La nueva ley señalaba, en su artículo 40 letra e), que el Consejo Superior debía pronunciarse sobre la revalidación de estudios, grados o títulos de otras instituciones de enseñanza superior nacionales y extranjeras, sin perjuicio de lo que era competencia exclusiva de otras universidades estatales. El inciso tercero del artículo 72 establecía que: "Corresponderá exclusivamente a la Universidad de Chile revalidar y reconocer, en conformidad a sus reglamentos internos, los grados académicos y títulos profesionales obtenidos mediante estudios efectuados en establecimientos extranjeros o internacionales de educación superior, sin perjuicio de lo dispuesto en los tratados internacionales" ${ }^{5}$.

2 Reyes Franzani, Juan de Dios, Reconocimiento de Exámenes, Grados y Títulos Profesionales Extranjeros en Chile y Ejercicio de Profesiones Liberales por Extranjeros en el País, Ed. Universitaria, Santiago de Chile, 1963.

3 Reyes, op. cit.

4 Reyes, op. cit.

5 Valdebenito Galindo, Rubén, "Responsabilidad de la Universidad de Chile en la Revalidación y Reconocimiento de Títulos Profesionales y Grados Académicos obtenidos en el Extranjero", en Reconocimiento y convalidación de Estudios Superiores y Títulos Profesionales en América Latina, Editado por Centro Interuniversitario de Desarrollo CINDA, 1998. 
Como se aprecia en las normas citadas, ha existido en forma continua una potestad de la Universidad de Chile en el reconocimiento y revalidación de títulos y grados obtenidos en instituciones extranjeras. Aparte de la constante histórica que las sustenta, tales disposiciones han tenido como ratio legis su carácter de universidad nacional y estatal, depositaria en esta materia de la fe pública, considerando su experiencia más que centenaria en el cultivo con excelencia de una amplia gama de disciplinas.

Por otra parte, cabe tener presente que, como ha señalado recientemente la Contraloría General de la República, la finalidad del reconocimiento, revalidación o convalidación de los estudios cursados en el extranjero tiene como fundamento la idea básica, propia del ordenamiento jurídico, de que el desarrollo de una actividad profesional en el país, tanto en el ámbito público como en el privado, sea realizada por una persona que acredite la idoneidad necesaria, acreditación que, ciertamente, debe hacerse con el mayor rigor y ante una entidad de la más alta competencia, particularmente por que dicho título o grado revalidado tendrá el mismo valor en Chile que uno otorgado por una universidad del Estado o reconocida por éste ${ }^{6}$.

\section{PROCEDIMIENTO DE REVALIDACIÓN Y RECONOCIMIENTO}

La Universidad de Chile ha reglamentado la atribución que establece el artículo $3^{\circ}$ de su Estatuto, en el Decreto Universitario N006.895 de 1993, Reglamento sobre Reconocimiento, Revalidación y Convalidación de Títulos Profesionales obtenidos en el Extranjero.

En general, se puede señalar que existen tres modalidades de validación de los estudios: la convalidación, el reconocimiento y la revalidación, todo ello sin perjuicio de los tratados internacionales suscritos por Chile.

La "convalidación" está destinada a establecer la equivalencia entre estudios cursados en una institución extranjera y las

6 Contraloría General de la República, Dictamen N²9.514 de 14 de julio de 2003. Sobre esta materia, también puede examinarse dictámenes №32.844 de 1982 y №27.922 de 1989, entre otros. 
correspondientes asignaturas que imparte la Universidad de Chile en un determinado plan de estudios. A partir de dicho análisis, la Universidad podrá establecer ciertas exigencias curriculares que el peticionario deberá cumplir: cursar asignaturas, rendir exámenes, realizar una práctica profesional o presentar monografías, memorias o tesis. La convalidación, en sí, no implica la habilitación para un desempeño universitario o profesional, sino que pretende fijar el nivel de formación académica que presenta un solicitante $y$, consecuencialmente, constituye un necesario antecedente para la revalidación o reconocimiento.

El "reconocimiento" acredita que los estudios realizados por una persona para la obtención de un grado académico o título profesional corresponden a una formación otorgada por instituciones extranjeras universitarias o superiores. Sólo procede cuando el título correspondiente tiene calidad de título profesional de nivel superior en el país de origen y no constituye requisito indispensable para el ejercicio profesional en Chile. En el caso de los grados académicos, sólo procederá el reconocimiento formal cuando habiliten para un ejercicio profesional en el país que los otorgó.

La "revalidación" de un título profesional obtenido en el extranjero procederá cuando se exija, necesariamente, el correspondiente título profesional chileno para el ejercicio profesional en el país.

Como se señaló, estos procedimientos buscan certificar ante la nación chilena la idoneidad del titulado en el extranjero para desempeñarse en nuestro país en determinada profesión. Considerando lo delicado que resulta una acreditación de este tipo, el procedimiento que se establece es bastante riguroso en cuanto a los antecedentes que se requieren al solicitante y a las actividades curriculares a las que, eventualmente, pueda ser sometido, lo que, además de medir su condición profesional, le permitirá profundizar su formación en las áreas propias de su ámbito.

La Prorrectoría de la Universidad de Chile es el ministro de fe de la institución y cumple la función de supervisar estos procesos. Los antecedentes son examinados por la unidad académica respectiva, la que recomienda el otorgamiento o denegación de la revalidación o, en 
su defecto, propone las actividades que el peticionario deberá cumplir como máximo en un año académico. En caso de requerirse un mayor plazo, la persona podrá postular a un ingreso especial a la carrera respectiva y tomar la calidad de alumno regular de la Universidad de Chile. Tratándose de títulos o grados académicos que ésta no ofrece, estudia los antecedentes una comisión especial establecida en la Vicerrectoría de Asuntos Académicos.

Una vez cumplidas las exigencias, la universidad otorga o deniega la revalidación del título a través de la resolución correspondiente y el diploma respectivo.

En el caso de los abogados, la universidad se limita a reconocer el grado de Licenciado en Ciencias Jurídicas y Sociales, por cuanto el título profesional lo otorga la Excelentísima Corte Suprema.

\section{TRATADOS INTERNACIONALES Y NORMAS ESPECIALES}

El Estado de Chile ha suscrito algunos tratados referentes a esta materia. Ellos son: el Convenio sobre mutuo reconocimiento de exámenes y de títulos profesionales entre Chile y Ecuador (Quito, 1917); la Convención sobre ejercicio de profesiones liberales suscrita entre Chile y Uruguay (Montevideo, 1916); la Convención sobre ejercicio de profesiones liberales suscrita entre Chile y Colombia (Santiago, 1921); el Convenio cultural entre Chile y España (Santiago, 1967) ${ }^{7}$; el Convenio de cooperación cultural y científica entre el Gobierno de la República de Chile y el Gobierno de la República Federativa del Brasil (Brasilia, 1976). Estos tratados, en general, reconocen recíprocamente los títulos y grados otorgados en los países contratantes y autorizan el ejercicio profesional, con excepción de requisitos formales extra-académicos (v.gr., la exigencia de nacionalidad para determinada profesión o el otorgamiento del título de abogado por la Corte Suprema). En el caso de estos acuerdos bilaterales, las personas acuden directamente al Ministerio de Relaciones Exteriores para que haga un registro de sus antecedentes, lo que constituye el acto habilitante.

7 El convenio con España se encuentra actualmente en una suerte de impasse, porque dicho país está sujeto a ciertas restricciones por sus recientes acuerdos con la Unión Europea, por lo cual los ciudadanos españoles hoy en día están validando sus títulos en Chile a través del sistema de revalidación en la Universidad de Chile. 
Existe, además, el Convenio Andrés Bello (suscrito por Chile, Bolivia, Colombia, Ecuador, España, Panamá, Perú y Venezuela, en Madrid, 1990) y el Convenio básico de cooperación educacional, de intercambio cultural y de becas entre Chile y Panamá (Panamá, 1962) que, entre otras materias, dan mutua validez a los estudios en los respectivos países firmantes, pero sólo para efectos de continuar estudios de posgrado o de especialización. En este caso, el grado o título se registra en el Ministerio de Educación y la persona postula al programa respectivo de acuerdo con las normas generales de selección e ingreso en la institución de su preferencia.

Dentro de los acuerdos internacionales quizás el de mayor interés sea la Convención de México para ejercicio de profesiones liberales (México,1902). Vigente, actualmente, para Bolivia, Costa Rica, Chile, El Salvador, Guatemala, Honduras, Nicaragua y Perú, establece que los ciudadanos de cualquiera de dichas repúblicas podrán ejercer, libremente, en el territorio de las otras la profesión para la cual estuvieren habilitados con un diploma o título expedido por la autoridad competente en cada uno de los países signatarios. Para hacerlo efectivo, deben registrarse los antecedentes debidamente autenticados en el Ministerio de Relaciones Exteriores. El artículo III de la Convención reserva para cada parte el derecho de exigir a los ciudadanos de las otras que se sometan a un previo examen general sobre los ramos de la profesión, para el caso de cualquier título relacionado con cirugía y medicina, incluyéndose el de farmacéutico. En Chile, tal examen lo toma la Universidad de Chile -por encargo del Ministerio de RR.EE.- en virtud de sus atribuciones en materia de validación de títulos extranjeros.

Finalmente, la Ley $19.074^{8}$ estableció un sistema especial para autorizar el ejercicio profesional a personas que obtuvieron títulos técnicos y profesionales en el exterior, habiendo salido del país antes del 11 de marzo de 1990, por razones de fuerza mayor, y retornado hasta el 31 de diciembre de 1995. Tales personas debían presentar sus antecedentes ante la Oficina Nacional de Retorno la que, a su vez, los remitía a una Comisión Especial presidida por el ministro de Educación e integrada por el rector de la Universidad de Chile, dos rectores de

8 Diario Oficial de 28 de agosto de 1991, modificada en 1993 por Ley 19.248. 
universidades tradicionales, tres integrantes del Consejo Universitario de la Universidad de Chile (uno de los cuales, al menos, debía ser decano de facultad), un representante de la asociación gremial correspondiente al título en trámite, y el director de la Oficina Nacional de Retorno (con derecho a voz). La comisión podía otorgar el reconocimiento o disponer que, previamente, se realizaran ciclos de estudio, trabajos prácticos o pruebas académicas en la Universidad de Chile o, excepcionalmente, en otra institución de educación superior en el caso de que la Universidad de Chile no impartiera tales estudios (por ejemplo, títulos técnicos). La resolución de la comisión reconocía el título o grado y lo inscribía en un registro especial en la Universidad de Chile. Corresponde al director jurídico de la Universidad de Chile certificar el hecho de la inscripción para efectos legales, siendo éste el documento que acredita erga omnes la autorización para el ejercicio profesional en nuestro país, en virtud de este estatuto especial.

\section{CONSIDERACIONES FINALES}

El proceso de globalización de la economía, el aumento de los acuerdos comerciales, el activo intercambio cultural y académico, las necesidades de transferencia tecnológica y la permanente creación de conocimiento son fenómenos que permiten prever el incremento sostenido del desempeño en nuestro país de profesionales titulados en el extranjero, y viceversa. Esto puede apreciarse en el siguiente cuadro, que muestra los reconocimientos y revalidaciones aprobados por la Universidad de Chile ${ }^{9}$ en cada uno de los años que se indican.

\begin{tabular}{|c|c|c|c|}
\hline Año & Reconocimientos & Revalidaciones & Total \\
1982 & 0 & 12 & 12 \\
1992 & 1 & 39 & 40 \\
2002 & 37 & 107 & 144 \\
\hline
\end{tabular}

Asimismo, existe una importante cantidad de graduados chilenos que están llevando a cabo estudios de posgrado en otros países, como también un buen número de extranjeros especializándose en Chile.

9 Datos de la Oficina de Títulos y Grados de la Universidad de Chile. 
Fluye de lo anterior la responsabilidad del Estado y de sus órganos, entre los cuales, por cierto, se incluye la Universidad de Chile, respecto de procurar a la ciudadanía la seguridad de que al contar con los servicios de un profesional graduado en el extranjero, pueda confiar en que su idoneidad se encuentra debidamente acreditada. Además, se debe velar para que el nivel de los profesionales y especialistas chilenos sea acorde con los estándares de calidad internacionales, de manera tal que puedan desempeñarse cabalmente en su área donde sean requeridos. Todo ello, teniendo presente el necesario equilibrio entre el dinamismo con que se desarrollan actualmente las relaciones internacionales, en el nivel público y privado, y el debido resguardo del prestigio logrado por nuestro país en el concierto mundial. 


\section{REFERENCIAS BiBLIOGRÁFICAS}

Marshall, Enrique L., Universidad de Chile, Leyes, Decretos y Reglamentos. Tomo I, Reglamentación General de los Servicios dependientes de Rectoría, Ed. Universitaria, Santiago de Chile, 1953.

Reyes Franzani, Juan de Dios, Reconocimiento de Exámenes, Grados y Títulos Profesionales Extranjeros en Chile y Ejercicio de Profesiones Liberales por Extranjeros en el País, Ed. Universitaria, Santiago de Chile, 1963.

Valdebenito Galindo, Rubén, "Responsabilidad de la Universidad de Chile en la Revalidación y Reconocimiento de Títulos Profesionales y Grados Académicos obtenidos en el Extranjero", en Reconocimiento y convalidación de Estudios Superiores y Títulos Profesionales en América Latina, Editado por Centro Interuniversitario de Desarrollo CINDA, 1998.

Recopilación de Leyes y Reglamentos, Tomo I, Contraloría Universidad de Chile, 2003. 
